\title{
Mapping Cropland Abandonment in Mountainous Areas Using an Annual Land-Use Trajectory Approach
}

\section{Wei Song $(\mathbb{0}$}

Key Laboratory of Land Surface Pattern and Simulation, Institute of Geographic Sciences and Natural Resources Research, Chinese Academy of Sciences, Beijing 100101, China; songw@igsnrr.ac.cn

Received: 4 July 2019; Accepted: 24 October 2019; Published: 25 October 2019

\begin{abstract}
In recent years, with the unceasing acceleration of China's urbanization and rapid development of the country's economy, cropland abandonment has become an ongoing issue, especially in mountainous areas. Mapping abandoned cropland using remote sensing technology is still challenging due to the difficulties in distinguishing abandoned cropland from fallowed land. In addition, there are few credible approaches to map timing and recultivation of abandoned cropland. In this context, this research developed an annual land-use trajectory approach to map different types of abandoned cropland based on freely available Landsat and HJ-1 satellite images with a spatial resolution of $30 \mathrm{~m}$. Based on this method, five types of cropland change, including one type of fallowed land and two types of abandoned land, were identified in a mountainous town of China (Zhongduo). In addition, the timing and recultivation of abandoned cropland were assessed. The accuracy of the abandonment map was assessed as high as $86.67 \%$. It was found that the percentages of spontaneous abandoned, induced abandoned, fallowed, stable, and lost cropland in Zhongduo were $23.16 \%, 8.40 \%$, $13.69 \%, 27.84 \%$, and $26.91 \%$ from 2012 to 2017 , respectively. The average time for spontaneously abandoned cropland was 3.45 years. Furthermore, $50.54 \%$ of the spontaneously abandoned cropland and $12.91 \%$ of induced abandoned cropland were recultivated due to fluctuating prices of agricultural products and materials, and the implemented land transfer policy.
\end{abstract}

Keywords: cropland abandonment; annual land-use trajectory; CART algorithm; mountainous areas; Zhongduo Town; China

\section{Introduction}

Cropland abandonment, an extreme manifestation of land marginalization [1], is an ongoing trend in both developed and developing countries worldwide [2], attracting great attention at a global level [2-5]. Due to rapid economic growth, urbanization and industrialization have been vigorously promoted in recent years, accelerating the transfer of the large rural labor force to urban areas [6]. In 2000, the number of rural migrant workers in Chinese cities reached 150 million; this figure increased to 269 million in 2013, accounting for $60-70 \%$ of the total rural labor population [7]. Due to the combined influences of rural-to-urban migrations and other natural socio-economic factors, cropland abandonment in China has intensified, making it an important issue.

Briefly, cropland abandonment is described as the cessation of cultivation in cropland for a certain period. However, the defined period of ceased cultivation remains the subject of debate [8]. For example, the Food and Agriculture Organization (FAO) defined abandoned cropland as cropland that has not been utilized for agricultural production or other agricultural purposes for at least five years [9], while the International Symposium on Land Consolidation and Land Reserve in 2011 defined cropland abandonment as two or more years [10]. In this study, the latter definition, i.e., ceased cultivation of cropland for at least two successive years, was adopted. Here, two years of successive cessation was emphasized to distinguish abandonment from fallowed land. In China, land fallowing 
is a new phenomenon that has emerged in recent years, although it remains unpopular due to the huge pressure for food security. Most fallowed land is uncultivated for one year [11,12].

The forms of cropland abandonment are spontaneous and induced [13]. Spontaneous cropland abandonment is an initiative of farmers based on their own planting decisions, while induced cropland abandonment is a result of policy guidance, such as the Common Agricultural Policy (CAP) in Europe and the Grain-for-Green Policy in China. The former policy encouraged the withdrawal of agricultural land from production [14-16], while the latter encouraged farmers to convert sloping cropland to forestry or grassland $[17,18]$.

In general, two types of approach have been adopted to estimate the scale of cropland abandonment in previous research: household surveys and remote sensing monitoring. The highest merit of the former approach is ease of use: There are few technical difficulties in using household surveys to assess the quantity of abandoned cropland. Therefore, many scholars have adopted the survey approach; for example, Li et al. [19] conducted a large-scale survey to estimate the extent of cropland abandonment in mountainous China and found that the average cropland abandonment rate was $14.32 \%$. In spatial, the abandoned cropland in China was found mostly distributed in southern China based on a meta-analysis [20]. A field survey from Nepal showed that nearly $46.6 \%$ of land has been abandoned due to the growth of market towns and urban centers, and the opening of the country to the international job market [21]. In the U.S., a farmers' perceptions survey of cropland abandonment showed that $28 \%$ of farm land owners considered some of their land abandoned [22]. While household surveys can easily acquire the quantity of abandoned cropland, their weakness is in mapping the spatial information of abandoned cropland. In addition, a typical survey cannot usually provide a full view of the whole cropland abandonment in the study area. In spite of the household survey and satellite image datum, the cadastral datum is a defendable datum to help mapping abandoned cropland [23]. However, in some regions such as China, there are no public cadastral databases, limiting the utilization of the cadastral datum.

Freely accessible satellite images have provided many datum sources to map abandoned cropland. Based on the spatial resolution of satellite images, the Moderate Resolution Imaging Spectroradiometer (MODIS), Landsat, and high-resolution satellite data, such as Quick-Bird, and aerial photographs are generally adopted to identify abandoned cropland. The advantage of the MODIS data is the high temporal resolution. However, the spatial resolution is low, $250 \mathrm{~m}$, which means that fragmented abandoned cropland usually cannot be identified. When MODIS datum has been used to extract abandoned cropland, the Normalized Difference Vegetation Index (NDVI) time series covering the whole growing season of crops was employed to detect the vegetation change [8]. The spatial resolution of Landsat data is about $30 \mathrm{~m}$, which is much higher than that of MODIS, and has the advantage of identifying fragmented abandoned cropland. However, due to the low temporal resolution (about $16 \mathrm{~d}$ ), it is usually difficult to find enough cloud-free images to establish long time series NDVI over a large region. Therefore, direct land use classification has been performed to capture land use conversions and identify abandoned cropland. The Random Forest model [24-26] and Support Vector Machine $[27,28]$ are the two most popular methods adopted to classify land use. In addition, other global or regional land use and land cover databases, such as the History Database of the Global Environment [29] and National Land Cover Database of the United States [30], have been used to assist in mapping abandoned cropland.

As remote sensing technology has improved, the spatial resolution of satellite images can reach one meter or better, providing more opportunities to map abandoned cropland. For example, researchers utilized Quick-Bird images and existing land use/land cover map layer to identify abandoned cropland in the Murcia Region of Southeast Spain [31]. In general, aerial photographs have higher spatial resolutions than those of satellite images. When identifying the abandoned cropland in topographically variable areas, such as gullies [32] and terraces [33,34], aerial photographs have been adopted. For ultra-high resolution tasks, aerial photographs are very useful for identifying detailed information regarding abandoned cropland, such as the height of succession vegetation after land abandonment [35] 
and the forest transition from deforestation to afforestation [36]. The advantages of high-resolution satellite images and aerial photographs are clear. However, there are also some disadvantages hindering the application of these data. Most high-resolution satellite images and aerial photographs are not freely available, and one scene of image or photograph only covers a very small area. This results in very high costs for identifying abandoned cropland, even in a relatively large region using these data. In addition, unlike satellite images, aerial photographs usually exist in few areas, and periodic updates are limited.

Although some research has been conducted in identifying abandoned cropland using remote sensing technology, huge challenges remain, e.g., differentiating abandoned cropland from fallowed cropland and recultivated abandoned cropland [2,8,24,26,34,37-40]. In prior work, abandoned cropland was usually identified by dividing the changes in vegetation or land use conversions using snapshots of land use data at the start and end years of a given research period. For example, Prishchepov et al. [27] mapped cropland abandonment in post-Soviet European Russia from 1990 to 2000 using the interpreted land use map in 1990 and 2000. Malavasi et al. [41] identified abandoned cropland in the Mediterranean mountain areas over a total span of 29 years using Landsat images in 1987, 2003, and 2016. This approach can either underestimate or overestimate the abandoned land. For the lack of continuous land use information, the timing of a certain land parcel's removal from cultivation cannot be accurately recorded. If the abandoned cropland plot, which was identified at the end of the time span, was just removed from cultivation for rotation, it should be fallowed land. Moreover, some active cropland identified at the end of a time span could also have been abandoned and recultivated. These possibilities generate some uncertainties in identifying cropland abandonment. In addition, distinguishing spontaneous abandonment from induced abandonment is particularly important for countries having implemented agricultural policies to intervene in land abandonment, and who want to better understand land abandonment behavior and the impacts of policy. Unfortunately, most previous research has not succeeded in differentiating the different types of abandonment.

To address the described challenges in mapping abandoned cropland and provide a technique support for policy making about addressing cropland abandonment, this research developed an annual land-use trajectory method to differentiate abandoned cropland land from fallow land, and to identify spontaneous and induced abandonment. By evaluating the timing of abandoned cropland, this research also assessed the recultivation of abandoned cropland. To reduce the cost of identification and effects of fragmented land parcels on identification, and to increase the transferability of the method, this research adopted freely available Landsat and HJ-1B images to conduct this research. In brief, the specific objective of this research is to develop a new approach to map different kinds of cropland abandonment in mountainous areas using free and medium resolution satellite images.

\section{Study Area and Data Sources}

\subsection{Study Area}

Youyang County is located in southeast Chongqing City, China, within the geographical range of $108^{\circ} 18^{\prime} 25^{\prime \prime}-109^{\circ} 19^{\prime} 02^{\prime \prime} \mathrm{E}$ and $28^{\circ} 19^{\prime} 28^{\prime \prime}-29^{\circ} 24^{\prime} 18^{\prime \prime} \mathrm{N}$ (Figure 1). It covers an area of $5173 \mathrm{~km}^{2}$ and governs two streets, 14 towns, and 23 townships. Zhongduo Town, the study area, is located in the middle of Youyang County, covers an area of $219 \mathrm{~km}^{2}$, and hosts the county government headquarters. The regional climate is humid subtropical monsoon climate with abundant precipitation, warm winters, and cool summers. Zhongduo lies within the Wuling mountain areas with an elevation difference of more than $1600 \mathrm{~m}$; central Zhongduo has a lower terrain, while the eastern and western parts are located at higher elevations. 



Figure 1. Geographical location of Zhongduo Town and a map of its land use in 2012; data source: The boundary was from the Resource and Environment Data Cloud Platform of Chinese Academy of Sciences. The classification result of Zhongduo in 2012 were from this research.

\subsection{Data Sources}

Considering the fragmented terrains in mountainous areas, the satellite images with a spatial resolution of $30 \mathrm{~m}$ were adopted. In total, 138 Landsat satellite images (Landsat 5 and Landsat 8 OLI ) covering Zhongduo from 2012 to 2017 were downloaded from the United States Geological Survey (USGS). Since Zhongduo is located in mountainous areas, cloud cover in most images is very high. After a cloud cover check, only ten scenes of satellite image remained with a cloud coverage of less than 10\%; of these, no images from 2012 were used because of the high cloud cover. Therefore, HJ-1B satellite images with a spatial resolution of $30 \mathrm{~m}$ from 2012 were adopted as supplementary image data. The HJ-1B images were download from China Centre for Resources Satellite Data and Application. The datum is a product of level two, which has performed radiation and geometric corrections. Atmospheric corrections on the images were conducted based on ENVI5.1 software and the extension tools entitled Data Reading Patch of HJ-1. The detailed band descriptions of Landsat 8 OLI and HJ-1B were shown in Table 1. 
Table 1. The band, wavelength, and spatial resolution of Landsat 8 OLI and HJ-1B.

\begin{tabular}{cccccc}
\hline & Landsat 8 OLI & & \multicolumn{3}{c}{ HJ-1B } \\
\hline Band & Wavelength/ $\boldsymbol{\mu m}$ & Resolution/m & Band & Wavelength/ $\boldsymbol{\mu m}$ & Resolution/m \\
\hline Band 1 & $0.433-0.453$ & 30 & Band 1 & $0.43-0.52$ & 30 \\
Band 2 & $0.450-0.515$ & 30 & Band 2 & $0.52-0.60$ & 30 \\
Band 3 & $0.525-0.600$ & 30 & Band 3 & $0.63-0.69$ & 30 \\
Band 4 & $0.630-0.680$ & 30 & Band 4 & $0.76-0.90$ & 30 \\
Band 5 & $0.845-0.885$ & 30 & Band 5 & $0.75-1.10$ & 150 \\
Band 6 & $1.560-1.660$ & 30 & Band 6 & $1.55-1.75$ & 75 \\
Band 7 & $2.100-2.300$ & 30 & Band 7 & $3.05-3.90$ & 90 \\
Band 8 & $0.500-0.680$ & 15 & Band 8 & $10.5-12.5$ & 300 \\
Band 9 & $1.360-1.390$ & 30 & & & \\
Band 10 & $10.60-11.19$ & 100 & & & \\
Band 11 & $11.50-12.51$ & 100 & & & \\
\hline
\end{tabular}

Give the phenological characteristics of crop production in Zhongduo and availability of satellite images, six scenes were ultimately adopted, including one HJ-1B satellite image from 2012 and five Landsat 8 OLI images from 2013 to 2017. All images were collected between June and October (Table 2). Here, this research combined satellite images of HJ-1B and Landsat 8 OLI to map abandoned cropland for the lack of available Landsat images in 2012. The classification results of the two kinds of satellite images could be comparable for the followed reasons. First, the spatial resolution of HJ-1B image $(30 \mathrm{~m})$ is the same with that of Landsat 8 OLI images. Second, the band information of the two kinds of satellite images can meet the requirements of classification method adopted in this paper. Third, this research mapped the abandoned cropland by detecting the successive land-use conversions during a certain period. In other words, this research only compared the results of land use classification of different years when mapping abandoned cropland. Last, some previous research [42,43] has convinced that the consistency of the classification result is very high when using Landsat 8 OLI and $\mathrm{HJ}-1 \mathrm{~B}$ images to map the land use of the same region separately.

Table 2. The acquisition date of adopted satellite images in this research.

\begin{tabular}{cccc}
\hline Scene ID & Acquisition Date & Resolution/m & Data Source \\
\hline HJ1B-CCD1-8-80-20121001-L20000861676 & $2012 / 10 / 01$ & 30 & HJ-1B \\
LC81260402013297LGN00 & $2013 / 10 / 24$ & 30 & LANDSAT8 \\
LC81260402014204LGN00 & $2014 / 07 / 23$ & 30 & LANDSAT8 \\
LC81260402015287LGN00 & $2015 / 10 / 14$ & 30 & LANDSAT8 \\
LC81270402016169LGN00 & $2016 / 06 / 17$ & 30 & LANDSAT8 \\
LC81260402017132LGN00 & $2017 / 05 / 12$ & 30 & LANDSAT8 \\
\hline
\end{tabular}

Google Earth images with a spatial resolution of $0.52 \mathrm{~m}$ were utilized to assist selecting training samples and assessing accuracy. These Google Earth images were downloaded using a 91 Satellite Imagery Assistant tool developed by the Digital Cloud Technology Co., Ltd. [44]. DEM datum, with a spatial resolution of $30 \mathrm{~m}$ from the Platform of Geospatial Data Cloud, were utilized to extract slope and elevation information. 


\section{Methods}

\subsection{A Framework for Identifying Abandoned Cropland}

This study adopted the definition of cropland abandonment from the International Symposium on Land Consolidation and Land Reserve in 2011, i.e., cropland that has not been cultivated for a minimum of two successive years. Cropland abandonment can be identified by detecting changes in vegetation or land use conversions. According to previous research, the vegetation succession after land abandonment in forest vegetation areas should be subject to annual and biennial weed, perennial grass and other grass, ligneous plants, and late succession species in sequence [45]. The changes from bare land to weeds or other grasses can take one to three years, to dwarf shrubs at least five years, and to trees at least ten years without human interference [46-48]. Therefore, spontaneous cropland abandonment should result in weeds or grasses as the dominant vegetation grown within the first three years of abandonment. However, with disturbance from human activities, vegetation succession can be sped up. China implemented the Grain-for-Green policy, its largest land retirement/afforestation program, in 2000. The policy encourages farmers to return sloping cropland to forests or grassland using human intervention. To promote the policy effects, vegetation was planted in the abandoned cropland to implement the policy, which sped up recovery [49-51]. For example, in mountainous areas, economic forest was usually planted to comply with the Grain-for-Green policy, which can reach full growth within three to five years [52]. This type of human intervention accelerated vegetation succession and created emerging forestry vegetation within a short period after abandonment.

In general, researchers cannot distinguish spontaneous cropland abandonment from induced cropland abandonment solely using land use conversions, because the two types of abandonment can generate similar land use conversions, i.e., from cropland to grassland or forest. Fortunately, based on the work of Shi and $\mathrm{Xu}$ [53] in Youyang, Wushan, and Shizhu County in Chongqing, the transitions from cropland to grassland resulting from the Grain-for-Green policy was negligible. Thus, the spontaneous and induced cropland abandonment in Zhongduo Town of Youyang County results in different land use conversions within a short period after abandonment. Spontaneous abandonment results in an initial conversion from cropland to grassland or bare land while induced abandonment, e.g., as part of the Grain-for-Green policy, would direct returning cropland to forestry, including shrubs and trees. By detecting different land use conversions, this research can differentiate spontaneous abandonment from induced abandonment.

Cropland fallowing is another activity associated with ceased cultivation, and it is easily confused with cropland abandonment. Different from cropland abandonment, cropland fallowed is a designed behavior to cease cultivation to let the land rest. The goal of this practice is to mitigate plant diseases and insect pests that proliferate due to overuse or to increase soil quality for better grain production $[54,55]$. Due to high grain production pressure, cropland fallowed intervals are usually short in China; one year is the most common interval $[12,56]$. Therefore, this research defined cropland fallowed as ceasing cultivation for one year (Table 3), which can be identified from the annual land use trajectory.

Based on the definitions in Table 3, a classification for cropland change was established, including stable cropland, abandoned cropland, fallowed cropland, and lost cropland. Abandoned cropland was further divided into two subclasses: Spontaneous and induced abandonment. Thus, this research identified the abandoned cropland by two steps. First, six land use types including cropland, forestry areas, grassland, water areas, and bare land were identified. Second, by monitoring successive land use conversions annually during the research period, the abandoned cropland was mapped. 
Table 3. Classification of different types of land abandonment in Zhongduo Town, China.

\begin{tabular}{ccc}
\hline Primary Class & Subclass & Definition \\
\hline Stable cropland & $\begin{array}{c}\text { Cropland in continuous cultivation throughout the } \\
\text { research period. }\end{array}$ \\
\hline Abandoned cropland & Spontaneous abandoned cropland & $\begin{array}{c}\text { Cropland that has been abandoned for at least successive } \\
\text { two years. }\end{array}$ \\
$\begin{array}{c}\text { Cropland that has been spontaneously abandoned by farmers. } \\
\text { The main vegetation grown in abandoned land is weeds or other } \\
\text { grasses within the research period. } \\
\text { Cropland that has been abandoned due to the Grain-for-Green } \\
\text { policy. The main vegetation grown in abandoned land are shrubs } \\
\text { or trees within the research period. }\end{array}$ \\
\hline Fallowed cropland & Induced abandoned cropland \\
\hline Lost cropland & Cropland where cultivation has ceased for one year. \\
\hline
\end{tabular}

\subsection{The Technique Flow for Mapping Abandoned Cropland}

Three steps were designed to map abandoned cropland in Zhongduo (Figure 2). First, a cropland boundary for 2012 based on the HJ-1 satellite images was created. To acquire the cropland boundary, land uses in whole Zhongduo in 2012 were mapped based on a CART algorithm. The training sample databases for HJ-1 satellite images classification were created by a visual interpretation of high-resolution Google Earth images. Totally 314 samples were selected to train CART model, including 51 samples of built-up areas, 102 samples of forestry areas, 6 samples of water areas, 80 samples of cropland land, 70 samples of grassland, and 5 samples of bare land. The cropland distribution in 2012 was extracted as the border for mapping abandonment. In the following step, annual land use from 2013 to 2017 within the 2012 cropland boundary was mapped. The CART algorithm was adopted again to map cropland land uses based on the training samples. Thus, dynamic land use maps within the cropland boundary were created. In the last step, the land-use trajectory at the pixel level was traced. The definitions in Table 3 were used to identify the five types of cropland change and map abandoned cropland.

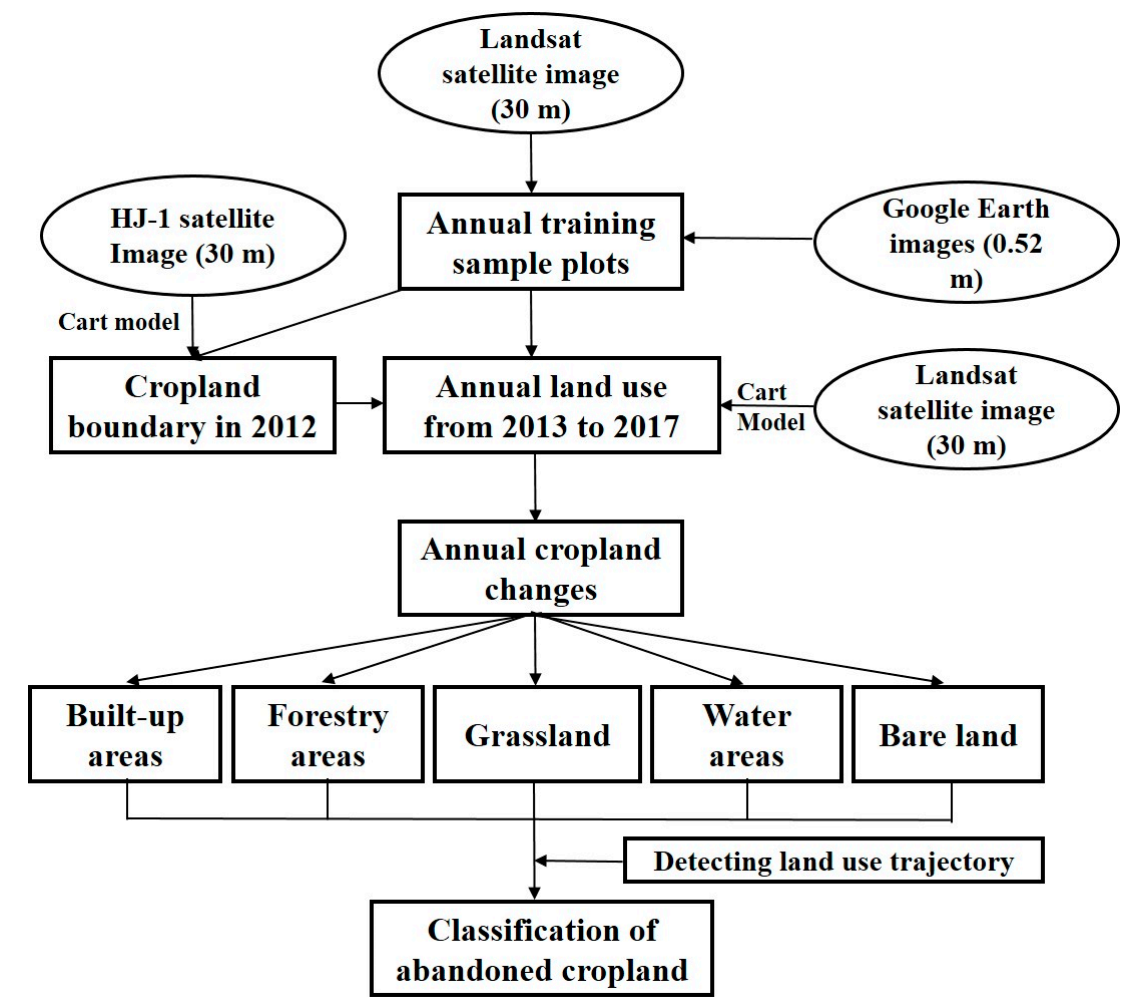

Figure 2. Flowchart for identifying abandoned cropland. 


\subsection{Mapping Land Use Using the CART Model}

Traditional remote sensing interpretation methods are based on the spectral characteristics of ground objects, which can be generally identified using the electromagnetic radiation information features received from remote sensing sensors. However, limited by the phenomena of "different objects with the same spectra characteristics, the same spectrum for different objects", these classification methods can show errors, such as wrong classification and omissive classification, depending on the spectral characteristics of ground objects $[57,58]$. In contrast, knowledge-based decision tree classification methods comprehensively use the remote sensing image and other spatial data, and then obtain the rules for remote sensing interpretation classification through methods such as expert experience summarization and simple mathematical statistical induction. In addition, these decision tree classification methods use multi-source data, which make the classification results superior to those of traditional interpretation methods.

This research adopted the CART algorithm to map land use, which is a type of effective nonparametric classification and regression method. First proposed by Breiman [59], it has gained extensive popularity in many fields, including statistics and tech mining [60]. In contrast to traditional statistics, the CART algorithm established prediction criterion in the form of a binary tree; it is therefore much easier to understand, interpret, and use related data. The Gini index, from economics, was used as the criterion to select the best test variables for measuring the impurity level of a sample classification or impurity level of a training sample set. A lower impurity level corresponds to a higher "purity" of sample [61]. The Gini index is defined as follows:

$$
\begin{gathered}
\operatorname{Gini}(S)=1-\sum_{j}^{J} p^{2}(j / h) \\
p(j / h)=\frac{n_{j}(h)}{n(h)}, \sum_{j}^{J} p(j / h)=1,
\end{gathered}
$$

where, $p(j / h)$ is the probability of a sample randomly selected from the training sample set belonging to the $j$-th class when the value of a certain test variable is $h ; n_{j}(h)$ is the sample number of the samples in the training sample set belonging to the $j$-th class of samples when the value of the test variable is $h$; $n(h)$ is the sample number in the training sample set when the value of the test variable is $h$; and $j$ is the class number.

In general, there are four steps to generate the decision tree using Gini index. First, Gini index of different attributes was calculated according the former equations. The attribute with the minimum Gini index was selected as the split attribute of the root node. For continuous attribute, the calculation of segmentation threshold is necessary for the purpose of discretization. For discrete attribute, samples should be divided into many subsets according to the value number of the attribute, and the subset with the minimum Gini index should be selected as the split attribute. Second, the sample set should be divided into two parts according to the value of the split attribute. Third, for the new generated two subsets, the works performed in the first step were repeated to find the child node. These circulations were kept on until all the samples within a subset belong to the same type or no available split attribute could be found. Last, cutting branches was performed to generate the final decision tree.

In this study, the specific process of running CART algorithm has followed several steps. Remote sensing images were first preprocessed and tailored. Subsequently, the NDVI layer, the 1-7 wave band layer, and ISODATA (Iterative self-organizing data analysis technique) unsupervised classification iteration layer (ten classes, ten times) were utilized to compound multi-source data. Here, ISODATA unsupervised classification and the EDVI was directly performed by ENVI5.1 software. The aim of conducting ISODATA unsupervised classification is to obtain abundant band information. By overlapping the images of Landsat 8 OLI, NDVI, and the results of ISODATA classification, a new multi-source datum layer was generated for classification. Then, the research extracted six training 
sample regions (including cropland, grassland, forestry, water, built-up areas, and bare land) using a false color layer and built a decision tree to map land use. One decision tree for 2012 utilized to map the cropland boundary is shown in Figure 3. ENVI Classic software and the CART extension tools were utilized to run the CART model.



Figure 3. Decision tree created to map land use of Zhongduo in 2012. Notes: B1 to B4 are the bands of HJ-1B from 1 to band 4, respectively. B5 is the NDVI, and B6 is the result of ISODATA classification. In addition, a total of seven decision trees were generated to conduct land use classification from 2012 to 2017. To save space, only one decision tree generated in 2012 was shown here.

The establishment of a decision tree has several steps (Figure 3). First, since the impervious surface areas has obvious ground object features, band 1 and 3 of HJ-1B satellite images were utilized to quickly identify built-up areas. For the identification of rest built-up areas, the result ISODATA classification was utilized. The framework of distinguishing grassland and forestry was similar to the extraction of built-up areas. The band information and threshold value were repeatedly adjusted to distinguish the rest land use types.

The overall accuracy was utilized to assess the accuracy of land use mapping using CART model. The overall accuracy is the proportion of total correctly classified pixels compared to the total number of pixels in the map $[62,63]$. The overall accuracy was calculated based on an error matrix generated by comparing reference data with classification results [64]. The reference data were generated by a visual photo-interpretation of the high-resolution Google Earth images. The overall accuracy can be automatically calculated using ENVI Classic software, and has been widely adopted to assess the accuracy of land use classification.

For comparison purposes, this research also used the supervised classification maximum likelihood method to map land use in 2012. It was found that the overall accuracy and Kappa coefficient of the land use map for Zhongduo in 2012 generated by CART algorithm are $92.78 \%$ and 0.89 (Table 4), respectively. This overall accuracy of CART algorithm is $9.22 \%$ higher than that of the maximum likelihood method, which performs the classification based on spectral information. 
Table 4. The error matrix of land use classification of Zhongduo in 2012 using CART algorithm.

\begin{tabular}{cccccccccc}
\hline Land Use & $\mathbf{1}$ & $\mathbf{2}$ & $\mathbf{3}$ & $\mathbf{4}$ & $\mathbf{5}$ & $\mathbf{6}$ & Total & $\mathbf{C E}$ & UA \\
\hline 1 & 77 & 0 & 0 & 5 & 0 & 15 & 97 & 20.6 & 79.4 \\
2 & 0 & 550 & 0 & 6 & 17 & 2 & 575 & 4.3 & 95.7 \\
3 & 0 & 0 & 21 & 0 & 0 & 0 & 21 & 0.0 & 100.0 \\
4 & 2 & 0 & 0 & 262 & 6 & 0 & 270 & 3.0 & 97.0 \\
5 & 0 & 21 & 0 & 8 & 150 & 1 & 180 & 16.7 & 83.3 \\
6 & 0 & 0 & 0 & 0 & 0 & 7 & 7 & 0.0 & 100.0 \\
Total & 79 & 571 & 21 & 281 & 173 & 25 & 1150 & & \\
OE & 2.5 & 3.7 & 0.0 & 6.8 & 13.3 & 72.0 & & & \\
PA & 97.5 & 96.3 & 100.0 & 93.2 & 86.7 & 28.0 & & & 92.78 \\
\hline
\end{tabular}

Notes: CE is committed error; OE is omitted error; UA is user accuracy; and PA is producer accuracy. Numbers of 1 , $2,3,4,5$, and 6 represent built-up areas, forestry, water, cropland, grassland, and bare land, respectively.

\subsection{Detecting Land Use Trajectory from 2012 to 2017}

To finally map abandoned cropland, the land-use trajectory at the pixel scale from 2012 to 2017 was calculated. By overlapping the cropland boundary in 2012 with the annual dynamic changes from 2013 to 2017, the land use-trajectories at the pixel level were created. With these trajectories, different types of cropland in Zhongduo were identified according to the definitions in Table 3.

In the land-use trajectory calculation, cropland unchanged throughout the research period, e.g., pixel $c$ (Figure 4), is classified as stable cropland. Lost cropland is identified according to the occurrence of built-up land. For example, croplands in pixel $e$ and $g$ were converted to built-up land in 2016 and 2014 , respectively. These pixels are all classified as lost cropland. Fallowed cropland and abandoned cropland are classified according to the successive time cultivation has ceased. For example, land-use trajectories in pixel $d$ and $h$ indicate that cultivation ceased in 2014 and 2012, respectively. However, in the following years, they are recultivated. According to the definition, they are classified as fallowed land. In pixels $a, b, f$, and $i$, cultivation ceased for five, two, four, and four years, respectively. These pixels are classified as abandoned cropland. In addition, pixels $f$ and $i$ do not appear as forests, while pixel $a$ and $b$ emerged forested during the research period (six years). Therefore, croplands in pixel $f$ and $i$ are identified as spontaneous abandonment, while cropland in pixels $a$ and $b$ are classified as induced abandonment, i.e., resulting from the Grain-for-Green policy. This method was utilized to map cropland abandonment in Zhongduo from 2012 to 2017.
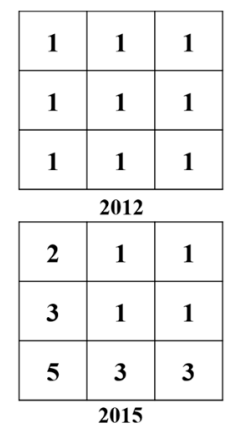

\begin{tabular}{|l|l|l|}
\hline$a$ & $b$ & $c$ \\
\hline$d$ & $e$ & $f$ \\
\hline$g$ & $h$ & $i$ \\
\hline
\end{tabular}
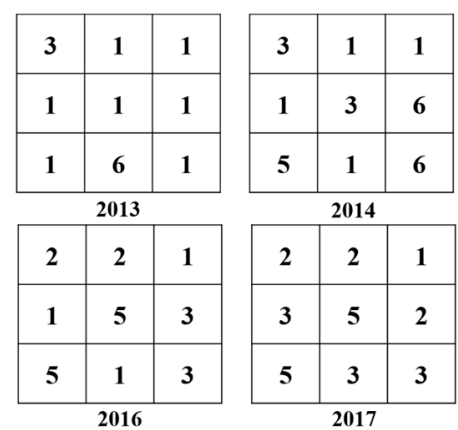

Notes: Number 1 is cropland;

$\mathbf{2}$ is forestry; $\mathbf{3}$ is grassland; $\mathbf{4}$ is

water; 5 is built-up areas; and 6 is

bare land.

Figure 4. Classification using land use trajectory detection. 


\subsection{Assessing the Accuracy of the Cropland Abandonment}

To verify the extraction accuracy of abandoned cropland, Google Earth images for Zhongduo in 2016 were downloaded. The resolution was set to $0.52 \mathrm{~m}$ and images were clear, enabling us to verify whether the abandoned land plots were correctly identified or not. A Total of 40 random points in Zhongduo were established based on ArcGIS software. Subsequently, three plots of mapped abandoned cropland near each sample point were created. Thus, the images corresponding to these 120 plots on the Google Earth base map were located to determine the status of the plot (Figure 5). After verification, 16 of these 120 plots were cultivated, indicating an identification accuracy of abandoned cropland of $86.67 \%$.
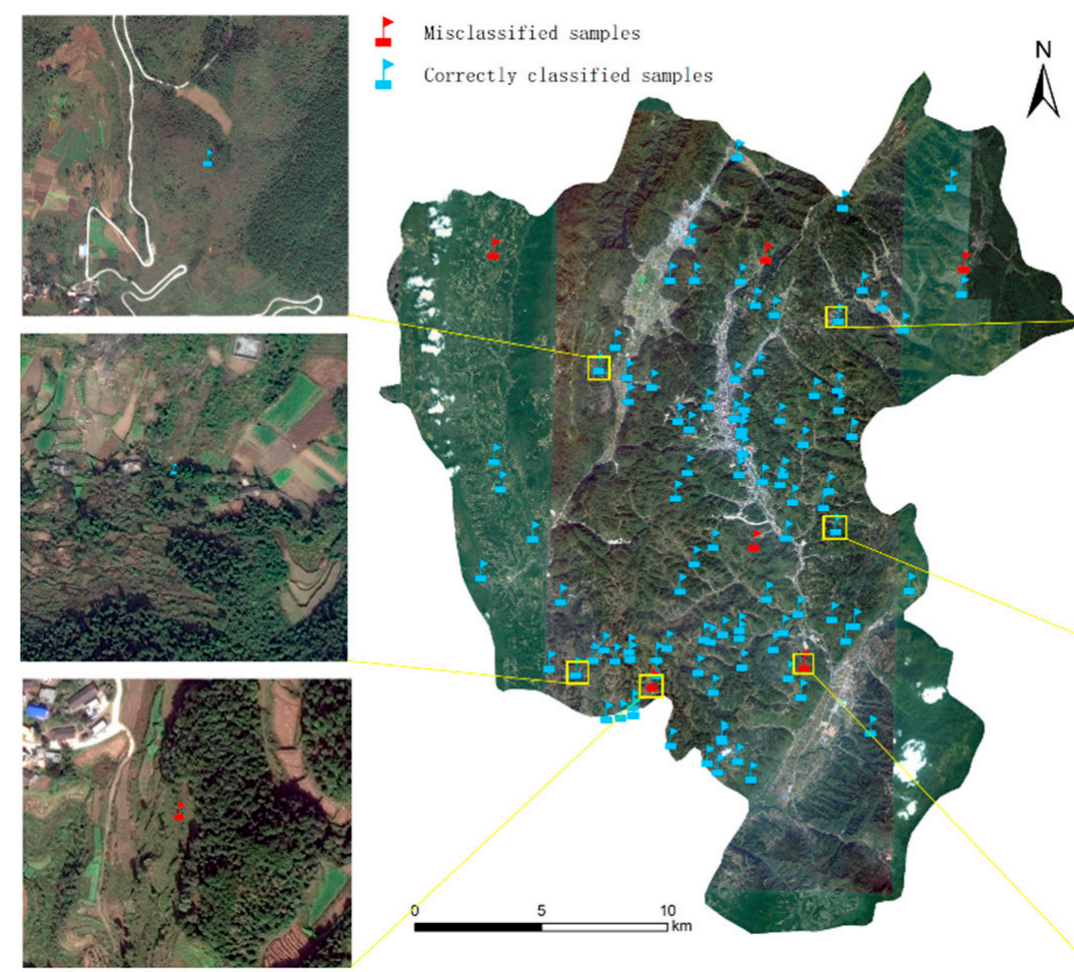

Figure 5. Samples used to assess accuracy.

Here, this research only assessed the accuracy of the total abandoned cropland. In Table 3, abandoned cropland was further divided into spontaneous and induced cropland. However, it is difficult to generate the verifying samples of spontaneous and induced cropland separately, only using Google Earth images of a certain year. This means that the classification accuracy of spontaneous and induced cropland cannot be assessed in this research. In the future, the problem could be solved by a detailed household survey. 


\section{Results}

\subsection{Land Use Patterns in Zhongduo in 2012}

In 2012, the land use type with the largest area in Zhongduo was forest, accounting for 53.67\% of the total area (Figure 1). Most forests were distributed in the Wuling Mountains, in southeast and north Zhongduo. Grassland was the second most-prevalent type, accounting for $26.13 \%$ of total area. Cropland, mainly scattered around rural settlements, was the third most-prevalent type, accounting for $17.15 \%$ of total area. Spatially, cropland and grassland presented a staggered distribution. Built-up areas were mainly distributed on both sides of the two highway roads, Baomao and Youyan, and concentrated in the central and southeastern parts of Zhongduo Town. Bare land only contributed $0.39 \%$ of total areas in Zhongduo, scattered on the southeast border and middle of the northeast.

\subsection{Distribution of Different Types of Cropland}

From 2012 to 2017, the proportion of abandoned cropland, fallowed cropland, stable cropland, and lost cropland to total cropland of 2012 were $31.56 \%, 13.69 \%, 27.84 \%$, and 26.91\%, respectively (Figure 6). Of the $31.56 \%$ abandoned cropland, $23.16 \%$ was spontaneous abandonment and $8.40 \%$ was induced abandonment. Generally, spontaneous abandoned cropland accounted for the largest cropland area, followed by stable cropland. Due to rapid economic development, built-up area expansion in Zhongduo was also substantial, resulting in a $26.91 \%$ loss of cropland.

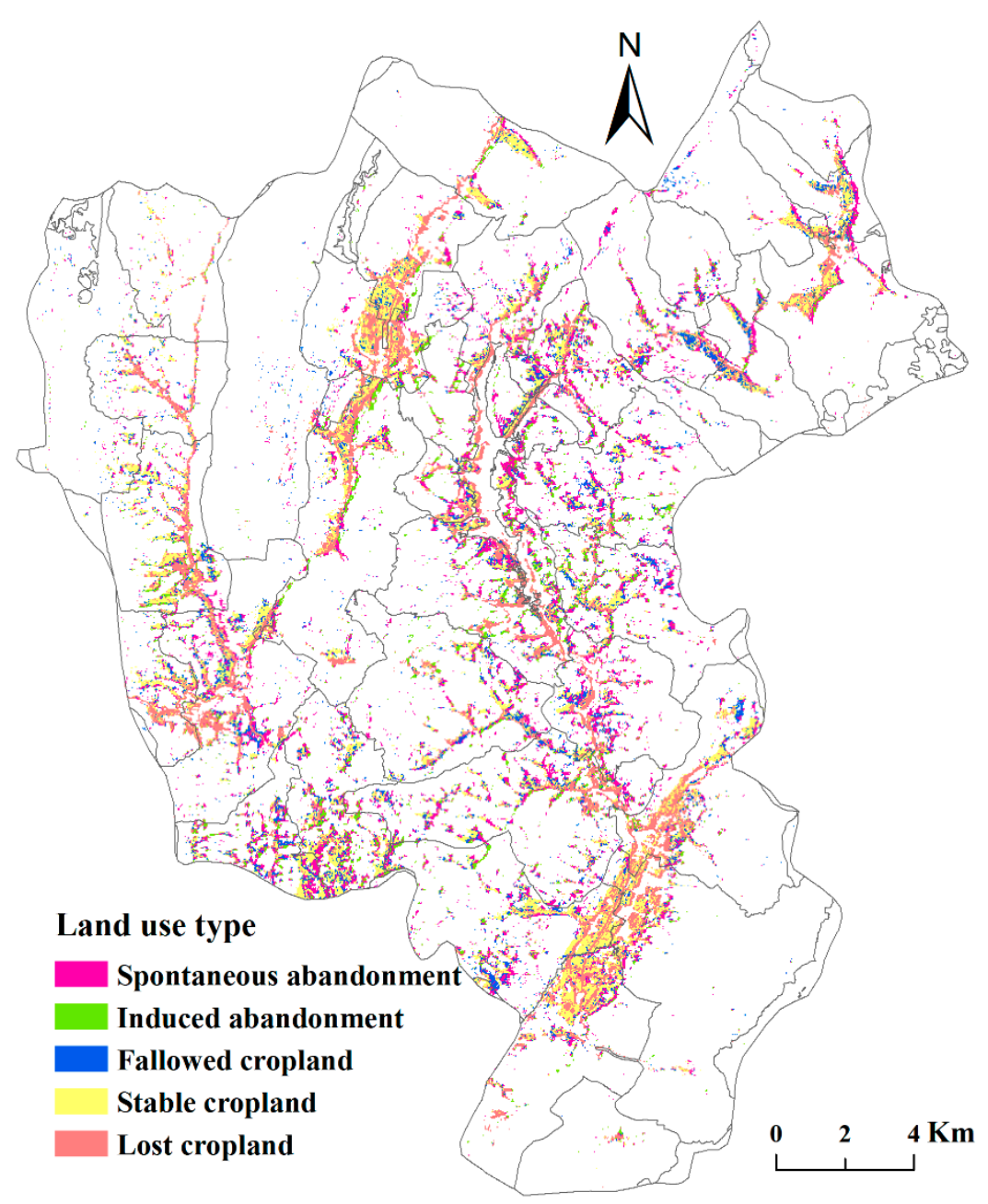

Figure 6. Different types of cropland in Zhongduo from 2012 to 2017. 
Spontaneous abandoned cropland was mainly distributed in Sanjiao and Zhaying Villages, southeast Zhongduo Town (Figure 7), and in Huayuan, Dongliukou, Chengnan, and Tonggu Villages along the Baomao highway; these six villages contributed $38.83 \%$ of the total area of spontaneous abandoned cropland. Induced abandoned cropland was mainly distributed in the villages of Liangjiapu, Chengnan, Guantang, and Yaoling, forming a ring around Qingshan Village in central Zhongduo; these four villages accounted for $28.41 \%$ of the total area of induced abandoned cropland. Fallowed cropland was mainly distributed in Tonggu, Guangtang, Yaoling, and Shanshuwan Villages in the southwest, and Zhongtuo village in the central-east; these villages accounted for $30.14 \%$ of total fallowed cropland. Stable cropland was mainly distributed in villages along the western border and in areas of two valleys, and lost cropland was mainly distributed in the two valleys of Zhongduo Town.

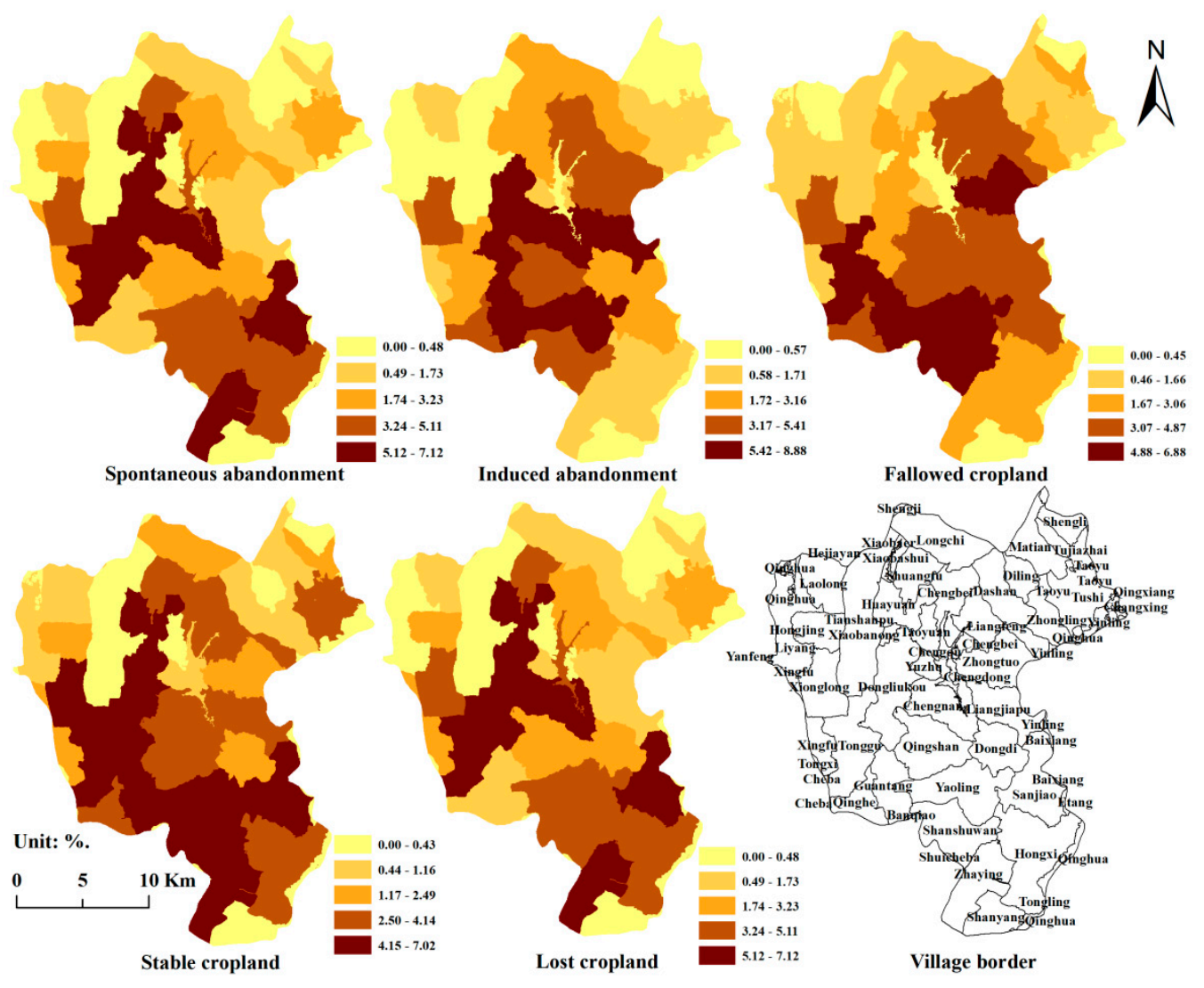

Figure 7. Percent distribution of different types of cropland at the village scale from 2012 to 2017.

\subsection{The Cropland Abandonment Rate}

To better discern the spatial features of cropland abandonment, a random raster with a resolution of $300 \mathrm{~m}$ was created, and the cropland abandonment rate in each pixel was calculated (Figure 8). As shown, serious spontaneous abandonment, with a rate of $77.79 \%$, was most prevalent in northeast central Zhongduo, central areas of Dongdi Village in southeast Zhongduo, and in the junction areas of Tonggu Village, Dongliukou Village, Qingshan Farm, and Guantang Village in southwest Zhongduo. In comparison, serious induced abandonment, with a rate of $75.01 \%$, mainly emerged in central Zhongduo. Serious land fallow, with a rate of $72.92 \%$, was primarily distributed in central-west Zhongduo. Compared to the scattered distribution of serious spontaneous abandonment across the whole town, areas showing serious induced abandonment and fallowed land were relatively concentrated.

In the three valleys where the terrain is relatively flat and the transportation convenient, croplands were easily lost, with a loss rate of $75.01 \%$ (Figure 8). Built-up expansions easily occur in these regions. The spatial pattern of stable cropland rate is similar with that of lost cropland rate, except for two 
regions: The first is the county seat region, where the lost cropland rate was high while the stable cropland rate was low, and the second is located in southwest Zhongduo, where the stable cropland rate was high and the cropland loss rate was low.

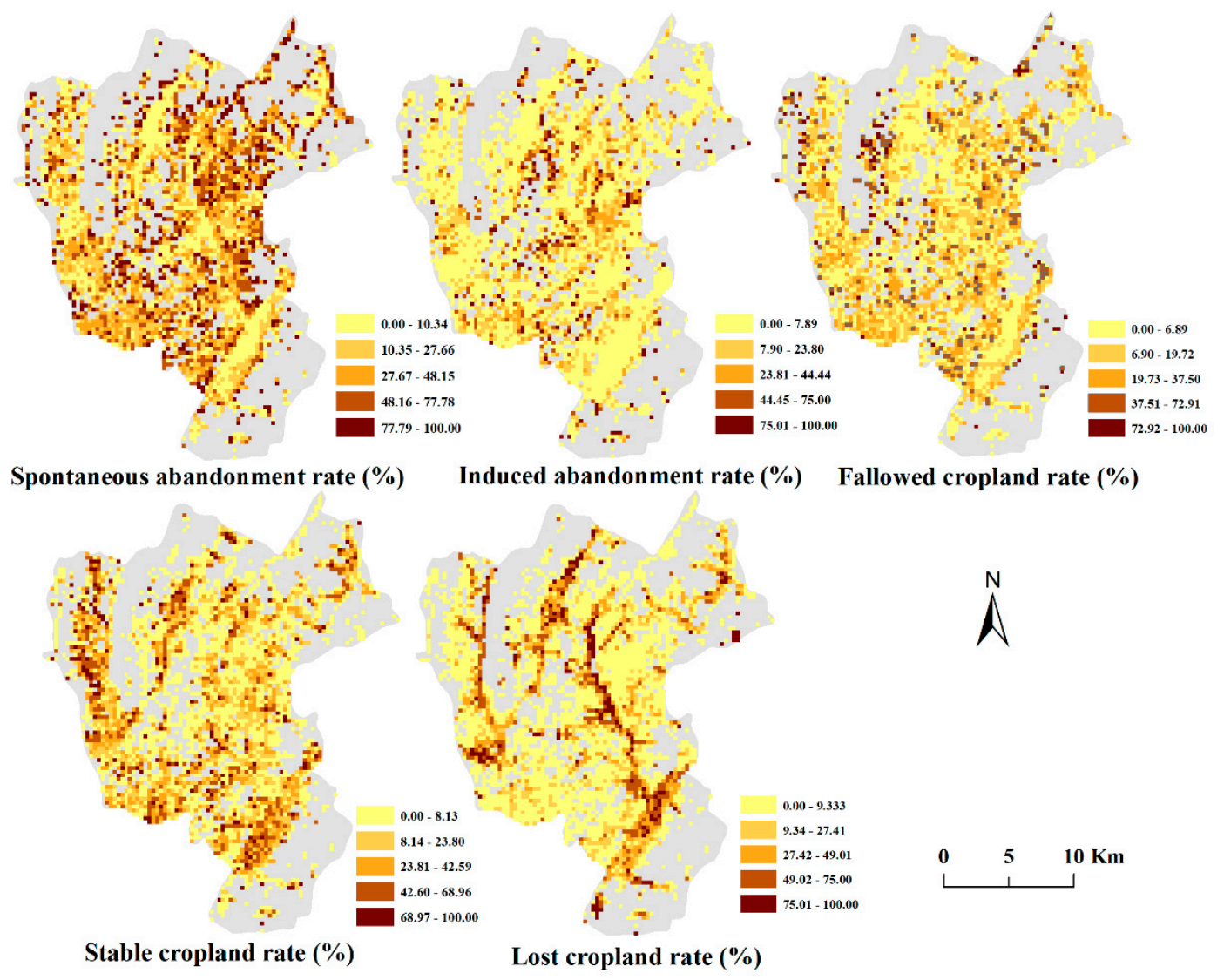

Figure 8. Cropland abandonment rate in Zhongduo from 2012 to 2017.

\subsection{Timing of Cropland Abandonment}

The mean duration time of spontaneous abandonment in Zhongduo was 2.84 years for 2012 to 2017. As shown in Figure 9, abandoned cropland with two, three, four, and five-year durations respectively accounted for $24.00 \%, 28.09 \%, 25.46 \%$, and $22.44 \%$ of the total abandonment areas. The cropland abandoned for three years accounted for the largest areas of spontaneous abandonment, while the cropland abandoned for five years contributed to the smallest proportion. Spatially, the cropland spontaneously abandoned for five years was mainly distributed in central and southwest Zhongduo. Cropland spontaneously abandoned for two years was scattered across all of Zhongduo. About $19.11 \%$ of spontaneously abandoned cropland was land fallowed before abandonment; accounting for time as fallowed prior to classification as abandoned, the average time of spontaneous abandonment reached 3.45 years. 


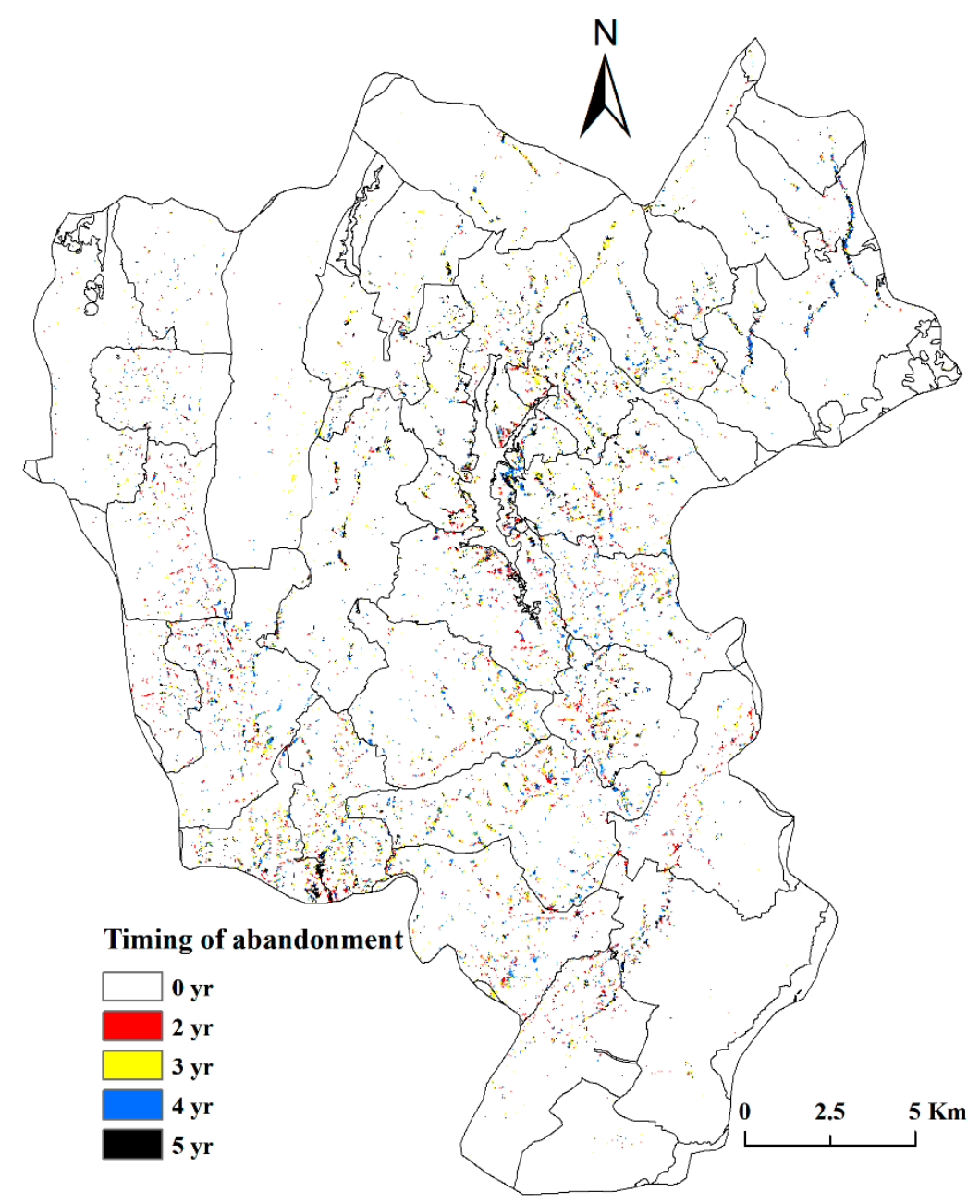

Figure 9. Timing of cropland abandonment in Zhongduo Town.

\section{Discussion}

\subsection{Land Quality of Abandoned Cropland}

Elevation and slope can reflect the land quality, while distance to rural settlement can reflect the convenience of cultivation. It was found that induced abandoned cropland had the largest elevation and slope among the five types of cropland, followed by spontaneous abandoned cropland and fallowed cropland (Table 5). The elevation and slope of stable cropland and lost cropland were clearly smaller than those of the other three types of cropland. The elevation and slope of lost cropland was respectively $89.64 \%$ and $50.40 \%$ of induced abandoned cropland. Features of distance to settlement for different types of cropland were similar to those for elevation and slope. From induced abandonment to spontaneous abandonment, fallowed cropland, stable land, and lost cropland, the cultivation convenience gradually increased $1.87 \%, 10.50 \%, 19.15 \%$, and $42.29 \%$, respectively. 
Table 5. Natural and distance conditions of different types of cropland.

\begin{tabular}{|c|c|c|c|}
\hline Type & Elevation (m) & Slope $\left({ }^{\circ}\right)$ & Distance to Rural Settlement (m) \\
\hline Spontaneous abandonment & 820.64 & 18.5 & 225.08 \\
\hline Induced abandonment & 826.29 & 19.76 & 229.37 \\
\hline Fallowed cropland & 806.01 & 15.8 & 205.29 \\
\hline Stable cropland & 776.76 & 12.7 & 185.68 \\
\hline Lost cropland & 740.67 & 9.96 & 132.38 \\
\hline
\end{tabular}

Notes: The distance from cropland to rural settlement here refers to the Euclid Distance instead of actual travel distance. In general, the actual travel distance will be much larger than the Euclid Distance considering the effects of topography.

From these results, it can infer that once the policies were implemented, farmers would prefer to surrender cultivating the worst quality cropland. In the remaining cropland, the inferior cropland faced greater risk of spontaneous abandonment, while the best cropland faced greater risk of encroachment by built-up expansion. Therefore, stable and fallowed croplands are mostly mid-quality. Furthermore, the quality of stable cropland is a little better than that of fallowed cropland.

It was found that the abandoned cropland was usually the poorest quality, findings similar to those from previous research. Zhang et al. [6] examined the effects of cropland-to-housing distance and land quality on cropland abandonment in Chongqing using household survey data. They found a higher probability of cropland abandonment on poorer quality land. Results from a household decision model developed using household survey data also from Chongqing showed that land parcels with higher land quality were less likely to be abandoned [65]. A multi-level analysis on cropland abandonment determinants in Chongqing using survey data showed that cropland abandonment is more common on plots with steeping slope, poor quality soil, and longer distances to laborer residences [17]. Finally, an influential factors analysis of the cropland abandonment at the township level in Chongqing showed that the average elevation, slope, and distance between townships and the county seat have significantly positive effects on abandonment [1]. More broadly, research from Southern Chile showed that land quality was a significant factor driving cropland abandonment [66], and in Slovakia, cropland abandonment was also more likely to occur on areas with lower land quality and with worse access to non-farmed land [67]. Our main findings indicating land quality is one of the key factors in cropland abandonment is consistent with these previous research studies.

\subsection{Changes in Spontaneous Cropland Abandonment Rate with Variations of Influence Factors}

In this study, it was found that the spontaneous abandonment rate for Zhongduo was $23.16 \%$. In nearby regions, several household surveys evaluating cropland abandonment were conducted, which can provide some comparison references. A household survey including 5258 plots of 599 rural households from Youyang and Wulong County found an average cropland abandonment rate of $25.60 \%$ [65]. The survey excluded abandonment resulting from the Grain-for-Green policy. Therefore, their result is very close to our spontaneous abandonment rate (23.16\%). In addition, Shi and Xu [53] developed an approach to map abandoned cropland in Shizhu, Wushan, and Youyang Counties in Chongqing. The approach identified abandoned cropland by overlapping two land use maps from different periods acquired from the local Land Resources and Management Bureau. In addition, a map layer of the locations implementing the Grain-for-Green policy from the local Forestry Bureau was utilized to exclude induced cropland abandonment. Their assessment showed that the cropland abandonment rate for Youyang County was $19.20 \%$. Using a similar approach, Shi et al. [1] assessed the cropland abandonment rate for 95 townships in Chong and found that the cropland abandonment rate in 29 towns ranged from 15 to $20 \%, 23$ towns from 10 to $15 \%$, and 15 towns from 20 to $25 \%$. Comparing the results from these prior studies with this research, the differences in the abandonment rate were between $2.44 \%$ and $3.96 \%$. Considering the minor differences in study areas and random error, the spontaneous abandonment rate of this research is very close to those found in previous work. 
With increasing elevation, slope, and cropland-to-settlement distance, the spontaneous abandonment rate increased gradually. However, the rate of increase did not continue to increase linearly (Figure 10). An inflection point emerged at certain elevations, slopes, and distances. For elevation, the inflection point was found between $1000 \mathrm{~m}$ to $1100 \mathrm{~m}$, where the spontaneous abandonment rate reached a peak of $47.61 \%$. Before this interval, the spontaneous abandonment rate increased rapidly with increasing elevation, while after this interval the spontaneous abandonment rate fluctuated and was more stable. A similar relationship was found for cropland-to-settlement distance; the inflection point emerged between $400 \mathrm{~m}$ and $500 \mathrm{~m}$ in distance, with an abandonment rate of $43.37 \%$. However, the relationship between spontaneous cropland abandonment rate and slope presented an inverted $U$ curve. When the slope exceeded $25^{\circ}$, the spontaneous abandonment rate gradually decreased with increasing slope; however, the total abandonment rate did not decrease above $25^{\circ}$. Because the Grain-for-Green policy in China was primarily implemented in cropland over $25^{\circ}$ slope $[18,68,69]$, at slopes greater than $20-25^{\circ}$, cropland abandonment gradually changed from spontaneous abandonment to induced abandonment.

\subsection{Stability of Cropland Abandonment}

Values for elevation, slope, and distance to rural settlement show continuously increasing trends with the increase of abandonment time (Table 6). This relationship indicates that poorer land quality corresponds to longer times for cropland abandonment. In addition, according to the land-use trajectory, it was found that $50.54 \%$ of the spontaneously abandoned cropland was recultivated after abandonment, while only $12.91 \%$ of induced abandoned cropland was recultivated. Induced abandonment is more stable than spontaneous abandonment due to worse land quality and subsidy incentives.

Abandoned cropland was recultivated for various reasons across different regions. Recultivation has been widespread in Eastern Europe [70], which has been explained by increased crude birth rates, changing ethnic minority populations, and grain yields [71]. In addition, foreign and domestic investments and price changes can play important roles in recultivating abandoned cropland. For example, in Russia, the Ukraine, and Kazakhstan, increasing investments and government support for agriculture production have resulted in recultivation [72]. These recultivated croplands usually have good land quality and access to convenient transportation. Moreover, recultivation has usually occurred within a relative short period after abandonment due to the low reclamation costs, as bushes or trees increase the costs of recultivation [73].

In Zhongduo, recultivation of abandoned cropland was primarily driven by agricultural product prices and land transfer policies. In general, as the price of agricultural products increase rapidly, farmers intend to recultivate the abandoned cropland with relatively good quality in the following years. In addition, as land transfer policies have been implemented, some abandoned cropland has been granted to large farming households for grain production. Because these factors can have a high uncertainty, e.g., crop prices, recultivation of abandoned cropland will be an episodic activity employed by farmers. 


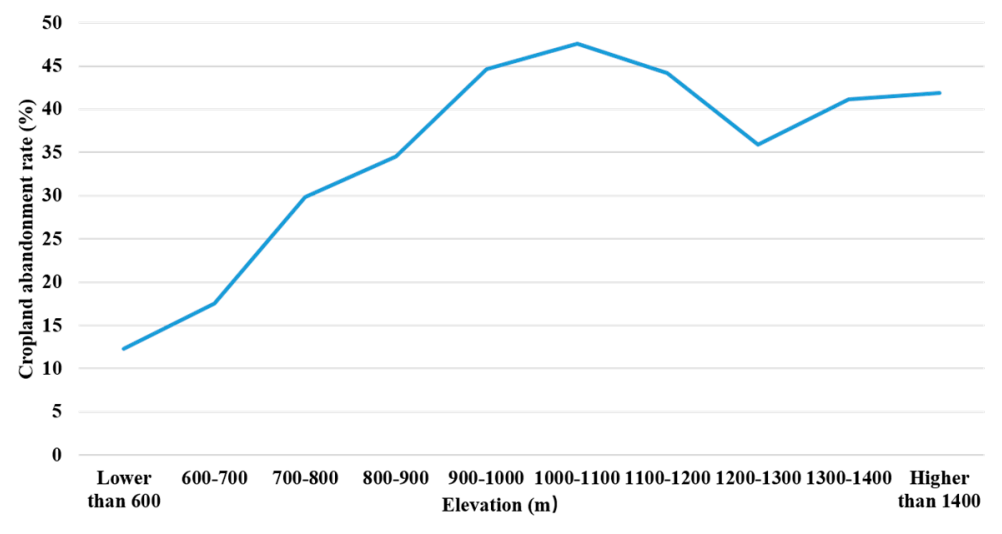

50

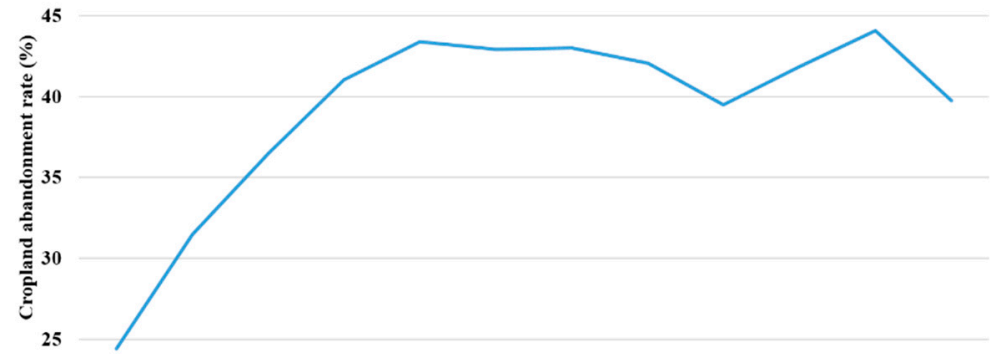

20

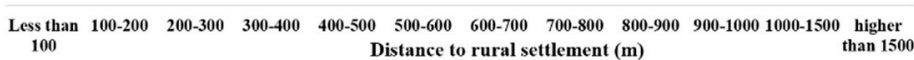

45

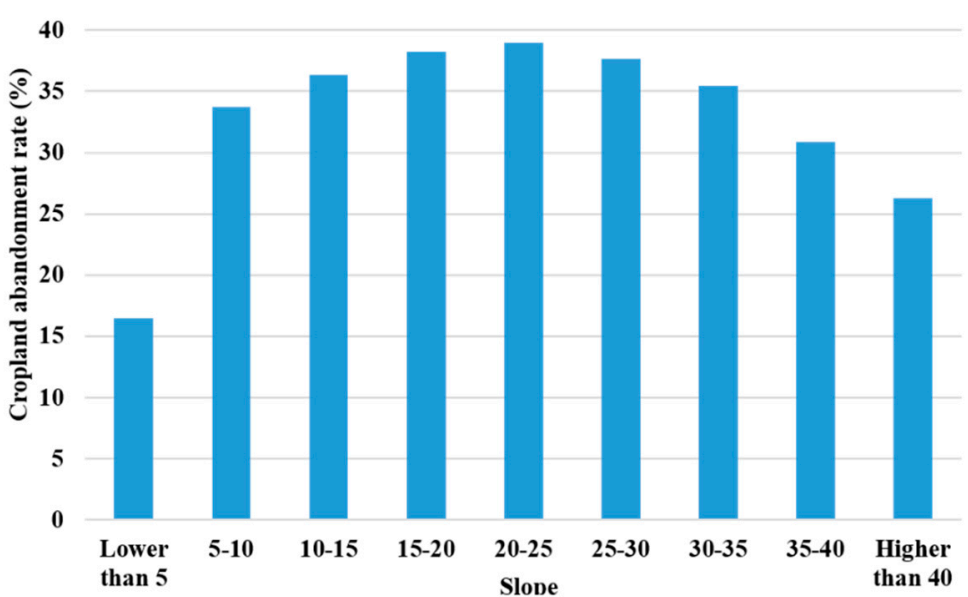

Figure 10. Changes in spontaneous abandonment rate with elevation, slope, and distance to rural settlement. 
Table 6. The relationship between slope, elevation, and distance conditions and cropland abandonment length.

\begin{tabular}{cccc}
\hline Type & Elevation $(\mathbf{m})$ & Slope $\left({ }^{\circ}\right)$ & Distance to Rural Settlement $(\mathbf{m})$ \\
\hline Non-abandonment & 793.12 & 14.75 & 198.41 \\
2 years & 799.77 & 17.22 & 207.95 \\
3 years & 815.36 & 17.85 & 231.20 \\
4 years & 822.35 & 18.55 & 225.22 \\
5 years & 836.44 & 19.84 & 229.79 \\
\hline
\end{tabular}

\subsection{Positives and Weaknesses of the Research}

This study developed a new approach to map abandoned cropland by monitoring the annual land-use trajectory of the study area. Comparing to the previous research $[1,5,8,13,14,20,26,28,46]$, there are two advantages and one weakness of the developed method. First, different from most of the previous research, this research detected the abandoned cropland by monitoring the consecutive land-use conversions during a certain period. This kind of research framework can effectively avoid the misclassification between fallowed cropland and abandoned cropland by detecting the time of abandonment. Second, an approach distinguishing spontaneous abandonment from induced abandonment was proposed in this research. This work has not been conducted in most of the previous research. However, this research needed to detect the annual land uses of study area. To accomplish this work, a consecutive and dynamic training sample database is necessary during the research period. The heavy work is a huge challenge when the method was transferred into a large region.

In this paper, Landsat 8 OLI and HJ-1B satellite images were utilized to identify the abandoned cropland. The merit of the data is that the images are all free access. Thus, the approach developed in this paper can be transferred into other regions of the world. In addition, the spatial resolution of the data is $30 \mathrm{~m}$, meeting most of the requirements of mapping abandoned cropland. However, there is one demerit for the data. The temporal resolution of the data is not very high. Thus, in some mountainous regions, the available Landsat images may not cover the whole region due to the limitation of clouds. This situation needs to couple multi-source data to accomplish the research.

\section{Conclusions}

This research developed an annual land-use trajectory approach to identify abandoned cropland in mountainous areas of China. By coupling a CART classification model and land-use trajectory tracing approach, the abandoned cropland in Zhongduo Town was mapped. To better describe the abandoned cropland, a detailed classification was proposed. Five types of cropland, spontaneously abandoned, induced abandoned, fallow, stable, and lost, were mapped. In addition, using the land-use trajectory trace approach, the timing and recultivation of abandoned cropland were mapped.

It was found that the average spontaneous abandonment rate in Zhongduo from 2012 to 2017 was $23.16 \%$, which is in good agreement with published household survey data from nearby regions. Among the abandoned and fallowed croplands, spontaneously abandoned cropland accounted for the largest proportion, $23.16 \%$, followed by fallowed cropland, $13.69 \%$, and induced, $8.40 \%$. Spontaneously abandoned cropland was abandoned for an average of 3.45 years. In addition, $50.54 \%$ of spontaneously abandoned cropland was recultivated in comparison to only $12.91 \%$ of induced cropland. The relatively good land quality and policy subsidy assisted in maintaining stable induced abandoned cropland. Fluctuations in agricultural production prices and the land transfer policy has resulted in recultivated spontaneously abandoned cropland. 
Funding: The research was supported by the Projects of National Natural Science Foundation of China (Grant No. 41671177), the Second Tibetan Plateau Scientific Expedition and Research (Grant No. 2019QZKK0603), the Opening Research Project of Key Laboratory of Land Use of Ministry of Natural Resources (No. 20191511228), the Key Research and Development Program of China (Grant No. 2016YFA0602402), the Program of Key Laboratory of Earth Observation and Geospatial Information Science of NASG (Grant No. 201807), and the Project of Research of Standards Drafting Expert Database from China National Institute of Standardization.

Acknowledgments: I thank Yuchen Guo for the help on creating training and reference data.

Conflicts of Interest: The author declares no conflict of interest.

\section{References}

1. Shi, T.; Li, X.; Xin, L.; Xu, X. The spatial distribution of farmland abandonment and its influential factors at the township level: A case study in the mountainous area of China. Land Use Policy 2018, 70, 510-520. [CrossRef]

2. Queiroz, C.; Beilin, R.; Folke, C.; Lindborg, R. Farmland abandonment: Threat or opportunity for biodiversity conservation? A global review. Front. Ecol. Environ. 2014, 12, 288-296. [CrossRef]

3. Xu, F.; Ho, H.C.; Chi, G.; Wang, Z. Abandoned rural residential land: Using machine learning techniques to identify rural residential land vulnerable to be abandoned in mountainous areas. Habitat Int. 2019, 84, 43-56. [CrossRef]

4. Shi, T.; Li, X.; Xin, L.; Xu, X. Analysis of Farmland Abandonment at Parcel Level: A Case Study in the Mountainous Area of China. Sustainability 2016, 8, 988. [CrossRef]

5. Zambon, I.; Ferrara, A.; Salvia, R.; Mosconi, M.E.; Fici, L.; Turco, R.; Salvati, L. Rural Districts between Urbanization and Land Abandonment: Undermining Long-Term Changes in Mediterranean Landscapes. Sustainability 2018, 10, 1159. [CrossRef]

6. Zhang, Y.; Li, X.; Song, W.; Zhai, L. Land abandonment under rural restructuring in China explained from a cost-benefit perspective. J. Rural Stud. 2016, 47, 524-532. [CrossRef]

7. Hao, P.; Tang, S. Floating or settling down: the effect of rural landholdings on the settlement intention of rural migrants in urban China. Environ. Plan. A Econ. Space 2015, 47, 1979-1999. [CrossRef]

8. Löw, F.; Prishchepov, A.; Waldner, F.; Dubovyk, O.; Akramkhanov, A.; Biradar, C.; Lamers, J. Mapping Cropland abandonment in the Aral Sea Basin with MODIS time series. Remote Sens. 2018, 10, 159. [CrossRef]

9. Rudel, T.K.; Schneider, L.; Uriarte, M.; Turner, B.L.; DeFries, R.; Lawrence, D.; Geoghegan, J.; Hecht, S.; Ickowitz, A.; Lambin, E.F.; et al. Agricultural intensification and changes in cultivated areas, 1970-2005. Proc. Natl. Acad. Sci. USA 2009, 106, 20675. [CrossRef]

10. Navarro, L.M.; Pereira, H.M. Rewilding Abandoned Landscapes in Europe. Ecosystems 2012, 15, 900-912. [CrossRef]

11. Lu, H.; Xie, H.; Lv, T.; Yao, G. Determinants of cultivated land recuperation in ecologically damaged areas in China. Land Use Policy 2019, 81, 160-166. [CrossRef]

12. Xie, H.; Wang, W.; Zhang, X. Evolutionary game and simulation of management strategies of fallow cultivated land: A case study in Hunan province, China. Land Use Policy 2018, 71, 86-97. [CrossRef]

13. García-Ruiz, J.M.; Lana-Renault, N. Hydrological and erosive consequences of farmland abandonment in Europe, with special reference to the Mediterranean region-A review. Agric. Ecosyst. Environ. 2011, 140, 317-338. [CrossRef]

14. Corbelle-Rico, E.; Crecente-Maseda, R.; Santé-Riveira, I. Multi-scale assessment and spatial modelling of agricultural land abandonment in a European peripheral region: Galicia (Spain), 1956-2004. Land Use Policy 2012, 29, 493-501. [CrossRef] 
15. Zakkak, S.; Kakalis, E.; Radović, A.; Halley, J.M.; Kati, V. The impact of forest encroachment after agricultural land abandonment on passerine bird communities: The case of Greece. J. Nat. Conserv. 2014, 22, 157-165. [CrossRef]

16. Juan, J.E.R.; Díaz, R. Evolution of land abandonment in the eastern region of murcia. Bol. Asoc. Geogr. Esp. 2016, 71, 457-462.

17. Zhang, Y.; Li, X.; Song, W. Determinants of cropland abandonment at the parcel, household and village levels in mountain areas of China: A multi-level analysis. Land Use Policy 2014, 41, 186-192. [CrossRef]

18. Song, W.; Pijanowski, B.C. The effects of China's cultivated land balance program on potential land productivity at a national scale. Appl. Geogr. 2014, 46, 158-170. [CrossRef]

19. Li, S.; Li, X.; Xin, L. Extent and distribution of cropland abandonment in Chinese mountainous areas. Resour. Sci. 2017, 39, 1801-1811.

20. Zhang, X.; Zhao, C.; Dong, J.; Ge, Q. Spatio-temporal pattern of cropland abandonment in China from 1992 to 2017: A Meta-analysis. Acta Geogr. Sin. 2019, 74, 411-420.

21. Khanal, N.R.; Watanabe, T. Abandonment of Agricultural Land and Its Consequences. Mt. Res. Dev. 2006, 26, 32-40. [CrossRef]

22. Kuntz, A.K.; Beaudry, F.; Porter, L.K. Farmers' Perceptions of Agricultural Land Abandonment in Rural Western New York State. Land 2018, 7, 128. [CrossRef]

23. Wang, T.; Kazak, J.; Han, Q.; De Vries, B. A framework for path-dependent industrial land transition analysis using vector data. Eur. Plan. Stud. 2019, 27, 1391-1412. [CrossRef]

24. Dara, A.; Baumann, M.; Kuemmerle, T.; Pflugmacher, D.; Rabe, A.; Griffiths, P.; Hölzel, N.; Kamp, J.; Freitag, M.; Hostert, P. Mapping the timing of cropland abandonment and recultivation in northern Kazakhstan using annual Landsat time series. Remote Sens. Environ. 2018, 213, 49-60. [CrossRef]

25. Schierhorn, F.; Müller, D.; Beringer, T.; Prishchepov, A.V.; Kuemmerle, T.; Balmann, A. Post-Soviet cropland abandonment and carbon sequestration in European Russia, Ukraine, and Belarus. Glob. Biogeochem. Cycles 2013, 27, 1175-1185. [CrossRef]

26. Yin, H.; Prishchepov, A.V.; Kuemmerle, T.; Bleyhl, B.; Buchner, J.; Radeloff, V.C. Mapping agricultural land abandonment from spatial and temporal segmentation of Landsat time series. Remote Sens. Environ. 2018, 210, 12-24. [CrossRef]

27. Prishchepov, A.V.; Müller, D.; Dubinin, M.; Baumann, M.; Radeloff, V.C. Determinants of agricultural land abandonment in post-Soviet European Russia. Land Use Policy 2013, 30, 873-884. [CrossRef]

28. Prishchepov, A.V.; Radeloff, V.C.; Dubinin, M.; Alcantara, C. The effect of Landsat ETM/ETM+ image acquisition dates on the detection of agricultural land abandonment in Eastern Europe. Remote Sens. Environ. 2012, 126, 195-209. [CrossRef]

29. Klein Goldewijk, K.; Beusen, A.; Doelman, J.; Stehfest, E. New anthropogenic land use estimates for the Holocene; HYDE 3.2. Earth Syst. Sci. Data 2016, 9, 927-953. [CrossRef]

30. Yu, Z.; Lu, C. Historical cropland expansion and abandonment in the continental U.S. during 1850 to 2016. Glob. Ecol. Biogeogr. 2018, 27, 322-333. [CrossRef]

31. Alonso-Sarría, F.; Martínez-Hernández, C.; Romero-Díaz, A.; Cánovas-García, F.; Gomariz-Castillo, F. Main Environmental Features Leading to Recent Land Abandonment in Murcia Region (Southeast Spain). Land Degrad. Dev. 2016, 27, 654-670. [CrossRef]

32. Golosov, V.; Yermolaev, O.; Rysin, I.; Vanmaercke, M.; Medvedeva, R.; Zaytseva, M. Mapping and spatial-temporal assessment of gully density in the Middle Volga region, Russia. Earth Surf. Process. Landf. 2018, 43, 2818-2834. [CrossRef] 
33. Poyatos, R.; Latron, J.; Llorens, P. Land Use and Land Cover Change After Agricultural Abandonment: The Case of a Mediterranean Mountain Area (Catalan Pre-Pyrenees). Mt. Res. Dev. 2003, 23, 362-368. [CrossRef]

34. Incze, J.; Novák, T.J. Identification of extent, topographic characteristics and land abandonment process of vineyard terraces in the Tokaj-Hegyalja wine region between 1784 and 2010. J. Maps 2016, 12, 507-513. [CrossRef]

35. Kolecka, N. Height of Successional Vegetation Indicates Moment of Agricultural Land Abandonment. Remote Sens. 2018, 10, 1568. [CrossRef]

36. Cervera, T.; Pino, J.; Marull, J.; Padró, R.; Tello, E. Understanding the long-term dynamics of forest transition: From deforestation to afforestation in a Mediterranean landscape (Catalonia, 1868-2005). Land Use Policy 2019, 80, 318-331. [CrossRef]

37. Alcantara, C.; Kuemmerle, T.; Prishchepov, A.V.; Radeloff, V.C. Mapping abandoned agriculture with multi-temporal MODIS satellite data. Remote Sens. Environ. 2012, 124, 334-347. [CrossRef]

38. Shao, J.a.; Zhang, S.; Li, X. Farmland marginalization in the mountainous areas: Characteristics, influencing factors and policy implications. J. Geogr. Sci. 2015, 25, 701-722. [CrossRef]

39. Terres, J.-M.; Scacchiafichi, L.N.; Wania, A.; Ambar, M.; Anguiano, E.; Buckwell, A.; Coppola, A.; Gocht, A.; Källström, H.N.; Pointereau, P.; et al. Farmland abandonment in Europe: Identification of drivers and indicators, and development of a composite indicator of risk. Land Use Policy 2015, 49, 20-34. [CrossRef]

40. Keenleyside, C.; Tucker, G.; McConville, A. Farmland Abandonment in the EU: An Assessment of Trends and Prospects. Available online: https://ieep.eu/uploads/articles/attachments/60c46694-1aa7-454e-828ac41ead9452ef/Farmland_abandonment_in_the_EU_-_assessment_of_trends_and_prospects_-_FINAL_1511-2010_.pdf?v=63664509740 (accessed on 1 June 2019).

41. Malavasi, M.; Carranza, M.; Moravec, D.; Cutini, M. Reforestation dynamics after land abandonment: A trajectory analysis in Mediterranean mountain landscapes. Reg. Environ. Chang. 2018, 18, 2459-2469. [CrossRef]

42. Shi, H.; Zhang, C.; Zhang, J.; Liang, C. Landsat8 and hj-1b sea surface temperature monitoring reliability and consistency studies. Geospat. Inf. 2017, 15, 67-70.

43. Gu, J.; Pei, L. Retrieval of Chlorophyll Content and Temperature in Taihu Based on Landsat 8-OLI /TIRS and HJ-1B. Geomat. Spat. Inf. Technol. 2017, 40, 146-151.

44. Beijing Qianfan Digital Cloud Technology Co., Ltd. Available online: http://b2b.huangye88.com/qiye2136492/ company_detail.html (accessed on 5 June 2019).

45. Brown, V.K.; Southwood, T.R.E. Secondary succession: Patterns and strategies. In Proceedings of Colonization, Succession and Stability: The 26th Symposium of the British Ecological Society; Gray, A.J., Crawley, M.J., Edwards, P.J., Eds.; Blackwell Science Inc.: Oxford, UK, 1987; pp. 315-337.

46. Nguyen, H.; Hölzel, N.; Völker, A.; Kamp, J. Patterns and Determinants of Post-Soviet Cropland Abandonment in the Western Siberian Grain Belt. Remote Sens. 2018, 10, 1973. [CrossRef]

47. Romero-Díaz, A.; Ruiz-Sinoga, J.D.; Robledano-Aymerich, F.; Brevik, E.C.; Cerdà, A. Ecosystem responses to land abandonment in Western Mediterranean Mountains. CATENA 2017, 149, 824-835. [CrossRef]

48. Smaliychuk, A.; Müller, D.; Prishchepov, A.V.; Levers, C.; Kruhlov, I.; Kuemmerle, T. Recultivation of abandoned agricultural lands in Ukraine: Patterns and drivers. Glob. Environ. Chang. 2016, 38, 70-81. [CrossRef]

49. Wang, X.; Wang, B.; Xu, X.; Liu, T.; Duan, Y.; Zhao, Y. Spatial and temporal variations in surface soil moisture and vegetation cover in the Loess Plateau from 2000 to 2015. Ecol. Indic. 2018, 95, 320-330. [CrossRef] 
50. Li, G.; Sun, S.; Han, J.; Yan, J.; Liu, W.; Wei, Y.; Lu, N.; Sun, Y. Impacts of Chinese Grain for Green program and climate change on vegetation in the Loess Plateau during 1982-2015. Sci. Total Environ. 2019, 660, 177-187. [CrossRef]

51. Ye, L.; Fang, L.; Shi, Z.; Deng, L.; Tan, W. Spatio-temporal dynamics of soil moisture driven by 'Grain for Green' program on the Loess Plateau, China. Agric. Ecosyst. Environ. 2019, 269, 204-214. [CrossRef]

52. Jiang, X.S.; Lan, Z.P.; Zhang, B.; Ma, K.; Hu, H.Z. Fixed monitoring of soil erosion in newly established cash crop tree plantations and rehabilitated bamboo forests. J. Beijing For. Univ. 2010, 32, 169-174.

53. Shi, T.; Xu, X. Extraction and validation of abandoned farmland parcel in typical counties of Chongqing. Trans. Chin. Soc. Agric. Eng. 2016, 32, 261-267.

54. Dharumarajan, S.; Lalitha, M.; Natarajan, A.; Naidu, L.G.K.; Balasubramanian, R.; Hegde, R.; Vasundhara, R.; Anil Kumar, K.S.; Singh, S.K. Biophysical and socio-economic causes for increasing fallow land in Tamil Nadu. Soil Use Manag. 2017, 33, 487-498. [CrossRef]

55. Ghosh, S.M.; Saraf, S.; Behera, M.D.; Biradar, C. Estimating Agricultural Crop Types and Fallow Lands Using Multi Temporal Sentinel-2A Imageries. Proc. Natl. Acad. Sci. USA India Sect. A Phys. Sci. 2017, 87, 769-779. [CrossRef]

56. Sun, M.; Gao, Z.-Q.; Ren, A.-X.; Deng, Y.; Zhao, W.-F.; Zhao, H.-M.; Yang, Z.-P.; He, L.-H.; Zong, Y.-Z. Contribution of Subsoiling in Fallow Period and Nitrogen Fertilizer to the Soil-water Balance and Grain Yield of Dry-land Wheat. Int. J. Agric. Biol. 2015, 17, 175-180.

57. Hayes, T.; Usami, S.; Jacobucci, R.; McArdle, J.J. Using Classification and Regression Trees (CART) and random forests to analyze attrition: Results from two simulations. Psychol. Aging 2015, 30, 911-929. [CrossRef] [PubMed]

58. Gholoobi, M.; Kumar, L. Using object-based hierarchical classification to extract land use land cover classes from high-resolution satellite imagery in a complex urban area. J. Appl. Remote Sens. 2015, 9, 096052. [CrossRef]

59. Breiman, L. Classification and Regression Trees. Routledge 2017. [CrossRef]

60. Rutkowski, L.; Jaworski, M.; Pietruczuk, L.; Duda, P. The CART decision tree for mining data streams. Inf. Sci. 2014, 266, 1-15. [CrossRef]

61. Timofeev, R. Classification and regression trees (CART) theory and applications. Master's Thesis, Humboldt University, Berlin, Germany, 2004.

62. Jin, Y.; Liu, X.; Chen, Y.; Liang, X. Land-cover mapping using Random Forest classification and incorporating NDVI time-series and texture: A case study of central Shandong. Int. J. Remote Sens. 2018, 39, 8703-8723. [CrossRef]

63. Zhang, C.; Sargent, I.; Pan, X.; Li, H.; Gardiner, A.; Hare, J.; Atkinson, P.M. Joint Deep Learning for land cover and land use classification. Remote Sens. Environ. 2019, 221, 173-187. [CrossRef]

64. Acharya, T.; Yang, I.; Lee, D. Land cover classification using a KOMPSAT-3A multi-spectral satellite image. Appl. Sci. 2016, 6, 371. [CrossRef]

65. Yan, J.; Yang, Z.; Li, Z.; Li, X.; Xin, L.; Sun, L. Drivers of cropland abandonment in mountainous areas: A household decision model on farming scale in Southwest China. Land Use Policy 2016, 57, 459-469. [CrossRef]

66. Díaz, G.I.; Nahuelhual, L.; Echeverría, C.; Marín, S. Drivers of land abandonment in Southern Chile and implications for landscape planning. Landsc. Urban Plan. 2011, 99, 207-217. [CrossRef]

67. Pazúr, R.; Lieskovský, J.; Feranec, J.; Ot’ahel', J. Spatial determinants of abandonment of large-scale arable lands and managed grasslands in Slovakia during the periods of post-socialist transition and European Union accession. Appl. Geogr. 2014, 54, 118-128. [CrossRef]

68. Feng, Z.; Yang, Y.; Zhang, Y.; Zhang, P.; Li, Y. Grain-for-green policy and its impacts on grain supply in West China. Land Use Policy 2005, 22, 301-312. [CrossRef]

69. Zhou, H.; Van Rompaey, A.; Wang, J.A. Detecting the impact of the "Grain for Green" program on the mean annual vegetation cover in the Shaanxi province, China using SPOT-VGT NDVI data. Land Use Policy 2009, 26, 954-960. [CrossRef]

70. Estel, S.; Kuemmerle, T.; Alcántara, C.; Levers, C.; Prishchepov, A.; Hostert, P. Mapping farmland abandonment and recultivation across Europe using MODIS NDVI time series. Remote Sens. Environ. 2015, 163, 312-325. [CrossRef] 
71. Meyfroidt, P.; Schierhorn, F.; Prishchepov, A.V.; Müller, D.; Kuemmerle, T. Drivers, constraints and trade-offs associated with recultivating abandoned cropland in Russia, Ukraine and Kazakhstan. Glob. Environ. Chang. 2016, 37, 1-15. [CrossRef]

72. Oecd. OECD Review of Agricultural Policies: Kazakhstan 2013; Oecd Publishing: Paris, France, 2013.

73. Larsson, S.; Nilsson, C. A remote sensing methodology to assess the costs of preparing abandoned farmland for energy crop cultivation in northern Sweden. Biomass Bioenergy 2005, 28, 1-6. [CrossRef]

(c)

(C) 2019 by the author. Licensee MDPI, Basel, Switzerland. This article is an open access article distributed under the terms and conditions of the Creative Commons Attribution (CC BY) license (http://creativecommons.org/licenses/by/4.0/). 